Article

\title{
Evaluation of the Pharmacokinetics of the Pancreastatin Inhibitor PSTi8 Peptide in Rats: Integration of In Vitro and In Vivo Findings
}

\author{
Guru R. Valicherla ${ }^{1,2}{ }^{(D}$, Roshan A. Katekar ${ }^{1,2}$, Shailesh Dadge ${ }^{1}$, Mohammed Riyazuddin ${ }^{1}$, Anees A. Syed ${ }^{1,2}$, \\ Sandeep K. Singh 1,2, Athar Husain ${ }^{1,2}$, Muhammad Wahajuddin 1,2 and Jiaur R. Gayen 1,2,3,*D
}

1 Pharmaceutics \& Pharmacokinetics Division, CSIR-Central Drug Research Institute (CSIR-CDRI), Lucknow 226031, India; gururaghava810@gmail.com (G.R.V.); roshankatekar123@gmail.com (R.A.K.); shailesh.dadge@gmail.com (S.D.); riyazuddinpharmacist@gmail.com (M.R.); syedaneesahmed5@gmail.com (A.A.S.); singhskbbd@gmail.com (S.K.S.); atharhusain001@gmail.com (A.H.); wahajuddin@gmail.com (M.W.)

2 Academy of Scientific and Innovative Research, Ghaziabad 201002, India

3 Pharmacology Division, CSIR-Central Drug Research Institute (CSIR-CDRI), Lucknow 226031, India

* Correspondence: jr.gayen@cdri.res.in; Tel.: +91-522-2772450 (ext. 4845)

Citation: Valicherla, G.R.; Katekar, R.A.; Dadge, S.; Riyazuddin, M.; Syed, A.A.; Singh, S.K.; Husain, A.; Wahajuddin, M.; Gayen, J.R. Evaluation of the Pharmacokinetics of the Pancreastatin Inhibitor PSTi8 Peptide in Rats: Integration of In

Vitro and In Vivo Findings. Molecules 2022, 27, 339. https://doi.org/ 10.3390/molecules27020339

Academic Editor:

Masahide Hamaguchi

Received: 8 November 2021

Accepted: 4 January 2022

Published: 6 January 2022

Publisher's Note: MDPI stays neutral with regard to jurisdictional claims in published maps and institutional affiliations.

Copyright: (C) 2022 by the authors. Licensee MDPI, Basel, Switzerland. This article is an open access article distributed under the terms and conditions of the Creative Commons Attribution (CC BY) license (https:// creativecommons.org/licenses/by/ $4.0 /)$.

\begin{abstract}
PSTi8 is a pancreastatin inhibitory peptide that is effective in the treatment of diabetic models. This study investigates the pharmacokinetic (PK) properties of PSTi8 in Sprague Dawley rats, for the first time. In vitro and in vivo PK studies were performed to evaluate the solubility, stability in plasma and liver microsomes, plasma protein binding, blood-plasma partitioning, bioavailability, dose proportionality, and gender difference in PK. Samples were analyzed using the validated LCMS/MS method. The solubility of PSTi8 was found to be 9.30 and $25.75 \mathrm{mg} / \mathrm{mL}$ in simulated gastric and intestinal fluids, respectively. The protein binding of PSTi8 was estimated as $>69 \%$ in rat plasma. PSTi8 showed high stability in rat plasma and liver microsomes and the blood-plasma partitioning was $>2$. The bioavailability of PSTi8 after intraperitoneal and subcutaneous administration was found to be $95.00 \pm 12.15$ and $78.47 \pm 17.72 \%$, respectively, in rats. PSTi8 showed non-linear PK in dose proportionality studies, and has no gender difference in the PK behavior in rats. The high bioavailability of PSTi8 can be due to high water solubility and plasma protein binding, low clearance and volume of distribution. Our in vitro and in vivo findings support the development of PSTi8 as an antidiabetic agent.
\end{abstract}

Keywords: antidiabetic drugs; PSTi8; in vitro ADME; in vivo pharmacokinetics; bioavailability

\section{Introduction}

In the 21st century, diabetes is one of the rapidly growing health challenges in the world. Globally, there are 537 million people living with diabetes in 2021, of which around $90 \%$ of the cases accounted for type 2 diabetes [1,2]. To date, existing drugs cannot completely cure type 2 diabetes, but they can manage glucose levels and prevent complications associated with the different organs [3,4]. There is a strong interest in the discovery and development of more effective drugs for the treatment of type 2 diabetes.

PSTi8 (PEGKGEQEHSQQKEEEEEMAV-amide), pancreastatin (PST) inhibitory peptide, was discovered and developed by the CSIR-Central Drug Research Institute (CSIRCDRI, Indian patent published 201611010438) [5]. PSTi8 has 21 amino acids with amidation at the C-terminal. The isoelectric point and charge at $\mathrm{pH} 7$ of the PSTi8 peptide, were observed as $\approx 4$ and -5 , respectively [6]. The PSTi8 peptide showed potent antidiabetic activity in several preclinical diabetes and insulin resistance (IR) models, such as diet-induced diabetes and IR mice, $\mathrm{db} / \mathrm{db}$ mice, diet-induced IR postmenopausal rats, dexamethasone induced type 2 diabetes mice and chronic hyperinsulinemia mice [5,7-10]. It is reported 
that PSTi8 showed antidiabetic activity by stimulating insulin signaling in the liver via AKT and PKC pathways, and inhibiting stress signaling in adipose via MAPK and NOX3-JNK pathways $[5,7,9]$. PSTi8 showed a decrease in the gluconeogenesis process in the liver, by downregulating gene expression levels, such as phosphoenolpyruvate carboxykinase and glucose- 6 -phosphatase $[5,7,8]$. The PSTi8 peptide was found to be safe and non-toxic with acute and chronic dose toxicity studies in C57Bl/6 mice [8]. PSTi8 is a highly potent antidiabetic peptide and the chronic dose used for antidiabetic activity in mice and rat models was 2 and $1 \mathrm{mg} / \mathrm{Kg}$, respectively [5,7].

Prior to the commencement of clinical studies, a comprehensive assessment of preclinical in vitro and in vivo PK information is a regulatory prerequisite for a better understanding of the efficacy, safety and toxicity profiles of investigational new drugs. In the current study, we investigate the in vitro and in vivo PK studies of PSTi8 for the first time in rats. In vitro studies, such as solubility, blood partitioning, plasma protein binding and stability in plasma and liver microsomes, were conducted to understand the disposition of PSTi8. PSTi8 was administered in different routes to evaluate bioavailability and PK behavior in male Sprague Dawley (SD) rats. The dose proportionality study was performed to determine the linear/non-linear PK pattern in male SD rats. Gender difference in PK studies was performed to perceive the differences in the PK parameters in male and female SD rats. The in vitro and in vivo PK knowledge obtained from this work is essential for the development of the PSTi8 peptide as a safe and effective antidiabetic drug.

\section{Results and Discussion}

\subsection{LC-MS/MS Bioanalytical Method}

In the recent report, we have described the LC-MS/MS method development and validation of PSTi8 in mice plasma [6]. No interference from the rat plasma matrix at the retention times of PSTi8 or diprotin A (internal standard, IS) was perceived, as shown in Figure S1. The linearity was accomplished using the area ratios of PSTi8 and IS across the calibration range of $5-1000 \mathrm{ng} / \mathrm{mL}$ concentrations with $\mathrm{r}^{2} \geq 0.997(n=6)$. The mean linear regression equation for PSTi8 in rat plasma was $y=0.00034 x+0.0059$ with a $1 / X^{2}$ weighing factor. The intra- and inter-day precision and accuracy results of the quality controls (QCs) were found within the acceptable criteria (Table S1). The intra- and inter-day accuracy of PSTi8 were found between 100.50-105.30\% and $99.88-103.98 \%$, respectively. The intra- and inter-day precision of PSTi8 were found between $2.29-3.64 \%$ and $5.73-8.43 \%$, respectively. The accuracy and precision results of the stability studies of PSTi8 were found within the criteria of an acceptable range. The PSTi8 peptide was found to be stable in rat plasma with diverse storage conditions (Table S2). We have successfully utilized the LC-MS/MS bioanalytical assay of the PSTi8 peptide for the evaluation of in vitro and in vivo PK properties. The plasma samples of PSTi8 collected after PK studies in rats were quantified by the validated assay together with the QC samples.

\subsection{Solubility Study}

The equilibrium solubility of PSTi8 in simulated gastric fluid (SGF) and simulated intestinal fluid (SIF) was found to be $9.30 \pm 0.40$ and $25.75 \pm 0.88 \mathrm{mg} / \mathrm{mL}$, respectively.

\subsection{Plasma Stability}

Plasma stability plays an important role in drug discovery and development. Unstable compounds tend to have rapid clearance and a short half-life, resulting in poor in vivo performance. The plasma stability profiles of PSTi8 are shown in Figure 1A. The stability of PSTi8 at 1 and $5 \mu \mathrm{M}$ concentrations was found to be $88.80 \pm 3.39$ and $90.56 \pm 6.65 \%$, respectively, at $4 \mathrm{~h}$ in rat plasma. 

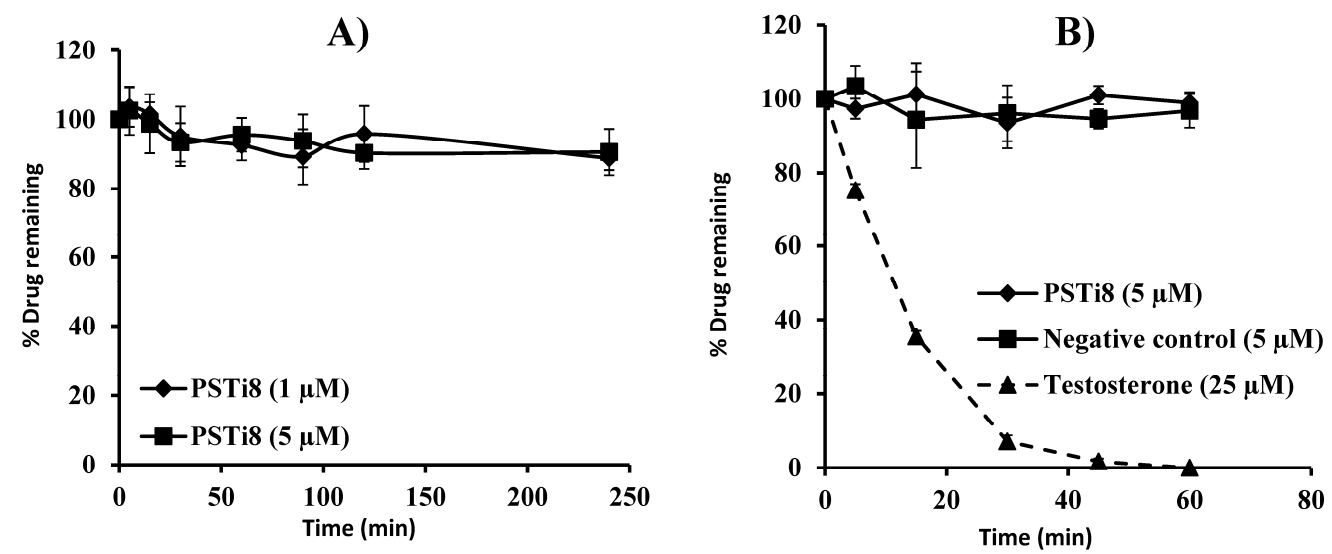

Figure 1. Stability of PSTi8 peptide in (A) rat plasma and (B) rat liver microsomes. Data are represented in $n=3$ with a mean $\pm \mathrm{SD}$.

\subsection{Microsomal Metabolic Stability}

Microsomal metabolic stability of PSTi8 was performed at a $5 \mu \mathrm{M}$ concentration in rat liver microsomes (RLM). Different RLM and nicotinamide adenine dinucleotide phosphate (NADPH) concentrations were tried to optimize the method. The PSTi8 peptide was found to be stable in RLM (Figure 1B) and has no degradation in the negative control experiment (without NADPH). The half-life of positive control (25 $\mu \mathrm{M}$ testosterone) was observed within the acceptable in-house limits.

\subsection{Plasma Protein Binding}

It is well known that only an unbound drug can reach the target site and exert its pharmacological action. Therefore, it is worthy to evaluate the unbound drug for identifying the parameters that affect the drug PK and pharmacodynamics. Ultrafiltration and equilibrium dialysis are common approaches for plasma protein binding estimation, but they have some drawbacks, such as nonspecific adsorption of the drugs to the device parts [11]. Therefore, a modified charcoal adsorption method was utilized for the protein binding estimation of PSTi8 in rat plasma. The modified charcoal adsorption method depends on the kinetics of charcoal adsorption and works in non-equilibrium conditions [12]. The plasma protein binding of PSTi8 at $2 \mu \mathrm{M}$ and $5 \mu \mathrm{M}$ was estimated as $73.63 \pm 0.91$ and $69.34 \pm 8.47 \%$, respectively, which suggest that it has high plasma protein binding. The plasma protein binding has a significant influence on drug PK parameters, such as clearance (CL/F) and apparent volume of distribution $\left(\mathrm{V}_{\mathrm{d}} / \mathrm{F}\right)$ [13]. The high plasma protein binding of PSTi8 explains the low $\mathrm{V}_{\mathrm{d}} / \mathrm{F}$ and $\mathrm{CL} / \mathrm{F}$ values observed in in vivo PK data.

\subsection{Blood-Plasma Partitioning}

The red blood cells (RBC): plasma partition coefficient $\left(\mathrm{K}_{\mathrm{RBC} / \mathrm{PL}}\right)$ values of PSTi8 at 0.206 and $0.412 \mu \mathrm{M}$ concentrations were found to be $2.46 \pm 0.44$ and $2.32 \pm 0.76$, respectively. The rate of RBC partitioning of PSTi8 was found to be rapid, as there was no significant difference ( $p>0.05$, Table 1$)$ between $\mathrm{K}_{\mathrm{RBC} / \mathrm{PL}}$ at various time points at the two concentrations.

\subsection{Evaluation of Preclinical PK Studies}

\subsubsection{Bioavailability Assessment in Different Routes of Administration}

The acute $(5 \mathrm{mg} / \mathrm{kg}$, intraperitoneal) administration of the PSTi8 peptide showed potential antidiabetic activity in postmenopausal IR rats [7]. Therefore, we used the same dose for the PK determination in different routes of administration. The PK profiles and parameters of PSTi8 peptide after intravenous (i.v.), intraperitoneal (i.p.) and subcutaneous (s.c.) dosing in male SD rats are represented in Figure 2A-C and Table 2. The maximum plasma concentration $\left(C_{\max }\right)$ was determined as $6047.77 \pm 348.49,4105.49 \pm 888.30$ and 
$30193.35 \pm 14562.01 \mu \mathrm{g} / \mathrm{L}$ concentrations after i.p., s.c. and i.v. administration of the PSTi8 peptide, respectively. The time to reach $\mathrm{C}_{\max }\left(\mathrm{T}_{\max }\right)$ of PSTi8 was found to be 0.48 and $0.60 \mathrm{~h}$ in i.p. and s.c. PK studies, respectively. The elimination half-life $\left(\mathrm{t}_{1 / 2}\right)$ of PSTi8 was observed as $0.44 \pm 0.10,0.42 \pm 0.004$ and $0.25 \pm 0.18 \mathrm{~h}$, following i.p., s.c. and i.v. dosing, respectively. The PSTi8 peptide rapidly reached its $C_{\max }$ and was eliminated with low $t_{1 / 2}$. The $V_{d} / F$ of PSTi8 after i.v., i.p. and s.c. administration was observed as $0.20 \pm 0.11$, $0.39 \pm 0.06$ and $0.46 \pm 0.09 \mathrm{~L} / \mathrm{kg}$, respectively. $\mathrm{V}_{\mathrm{d}}$ was less than $0.668 \mathrm{~L} / \mathrm{kg}$ (total body water) in rats, which specifies that the PSTi8 peptide has a low tissue distribution [14]. The CL/F of PSTi8 was observed as $0.60 \pm 0.10,0.62 \pm 0.08$ and $0.77 \pm 0.16 \mathrm{~L} / \mathrm{h} / \mathrm{kg}$ after i.v., i.p. and s.c. dosing, respectively. The CL values of PSTi8 were lower than $1.74 \mathrm{~L} / \mathrm{h} / \mathrm{kg}$ (hepatic plasma flow), which indicates that PSTi8 peptide has low extraction. After i.p., s.c., and i.v. administration, the area under curve (AUC) of PSTi8 was determined as $8099.23 \pm 1035.68$, $6690.13 \pm 1510.57$ and $8525.66 \pm 1604.03 \mathrm{~h}^{*} \mu \mathrm{g} / \mathrm{L}$, respectively. The absolute bioavailability of the PSTi8 peptide for i.p. and s.c. was $95 \pm 12.15$ and $78.47 \pm 17.72 \%$, respectively, which suggests that it has a high bioavailability. The high aqueous solubility, low $\mathrm{V}_{\mathrm{d}} / \mathrm{F}$, low CL/F and high plasma protein binding properties of PSTi8, can be responsible for the high bioavailability after i.p. and s.c. dosing in rats. The PSTi8 bioavailability for i.p. was reported as 52\% in mice [6], which demonstrates that the PSTi8 peptide has high and moderate i.p. bioavailability in rats and mice, respectively. The difference in the bioavailability of PSTi8 in rats and mice can be due to the physiological differences in these species. After i.p. treatment, PSTi8 showed higher plasma concentrations, $\mathrm{C}_{\max }, \mathrm{AUC}$ and bioavailability than the s.c. treatment. Therefore, we performed the dose proportionality and gender difference studies for the PSTi8 peptide using the i.p. treatment in rats.

Table 1. $\mathrm{K}_{\mathrm{RBC} / \mathrm{PL}}$ of PSTi8 in rat whole blood at $0.206 \mu \mathrm{M}$ and $0.412 \mu \mathrm{M}$. Data are presented as the mean \pm SD with $n=3$.

\begin{tabular}{|c|c|c|c|}
\hline \multirow{2}{*}{ Time (min) } & \multicolumn{2}{|c|}{$\mathrm{K}_{\mathrm{RBC} / \mathrm{PL}}$} & \multirow{2}{*}{$p$-Value } \\
\hline & Conc. $(0.206 \mu \mathrm{M})$ & Conc. $(0.412 \mu \mathrm{M})$ & \\
\hline 0 & $1.83 \pm 0.48$ & $2.23 \pm 0.02$ & 0.22 \\
\hline 15 & $2.56 \pm 0.25$ & $2.94 \pm 0.62$ & 0.38 \\
\hline 30 & $1.88 \pm 0.25$ & $2.55 \pm 0.65$ & 0.17 \\
\hline 45 & $2.05 \pm 0.12$ & $2.19 \pm 0.12$ & 0.22 \\
\hline 60 & $2.46 \pm 0.45$ & $2.33 \pm 0.77$ & 0.81 \\
\hline
\end{tabular}

Table 2. Pharmacokinetic parameters of the PSTi8 peptide after i.v., i.p. and s.c. administration at $5 \mathrm{mg} / \mathrm{kg}$ in male SD rats. Data are presented as the mean \pm SD with $n=6$.

\begin{tabular}{cccc}
\hline \multirow{2}{*}{ Parameters } & \multicolumn{3}{c}{ PSTi8 5 mg/kg } \\
\cline { 2 - 4 } & i.v. & i.p. & s.c. \\
\hline AUC $\left(\mathrm{h}^{*} \mu \mathrm{g} / \mathrm{L}\right)$ & $8525.66 \pm 1604.03$ & $8099.23 \pm 1035.68$ & $6690.13 \pm 1510.57$ \\
$\mathrm{C}_{\max }(\mu \mathrm{g} / \mathrm{L})$ & $30193.35 \pm 14562.01$ & $6047.77 \pm 348.49$ & $4105.49 \pm 888.30$ \\
$\mathrm{~T}_{\max }(\mathrm{h})$ & - & 0.48 & 0.60 \\
$\mathrm{CL} / \mathrm{F}(\mathrm{L} / \mathrm{h} / \mathrm{kg})$ & $0.60 \pm 0.10$ & $0.62 \pm 0.08$ & $0.77 \pm 0.16$ \\
$\mathrm{~V}_{\mathrm{d}} / \mathrm{F}(\mathrm{L} / \mathrm{kg})$ & $0.20 \pm 0.11$ & $0.39 \pm 0.06$ & $0.46 \pm 0.09$ \\
$\mathrm{~K}_{01}$-HL $(\mathrm{h})$ & - & $0.26 \pm 0.09$ & $0.41 \pm 0.01$ \\
$\mathrm{~K}_{10}-\mathrm{HL}(\mathrm{h})$ & $0.25 \pm 0.18$ & $0.44 \pm 0.10$ & $0.42 \pm 0.004$ \\
$\mathrm{~K}_{01}(1 / \mathrm{h})$ & - & $2.90 \pm 0.89$ & $1.68 \pm 0.02$ \\
$\mathrm{~K}_{10}(1 / \mathrm{h})$ & $3.79 \pm 2.19$ & $1.63 \pm 0.33$ & $1.66 \pm 0.01$ \\
MRT $(\mathrm{h})$ & $0.36 \pm 0.26$ & - & - \\
Bioavailability $(\%)$ & - & $95.00 \pm 12.15$ & $78.47 \pm 17.72$ \\
\hline
\end{tabular}



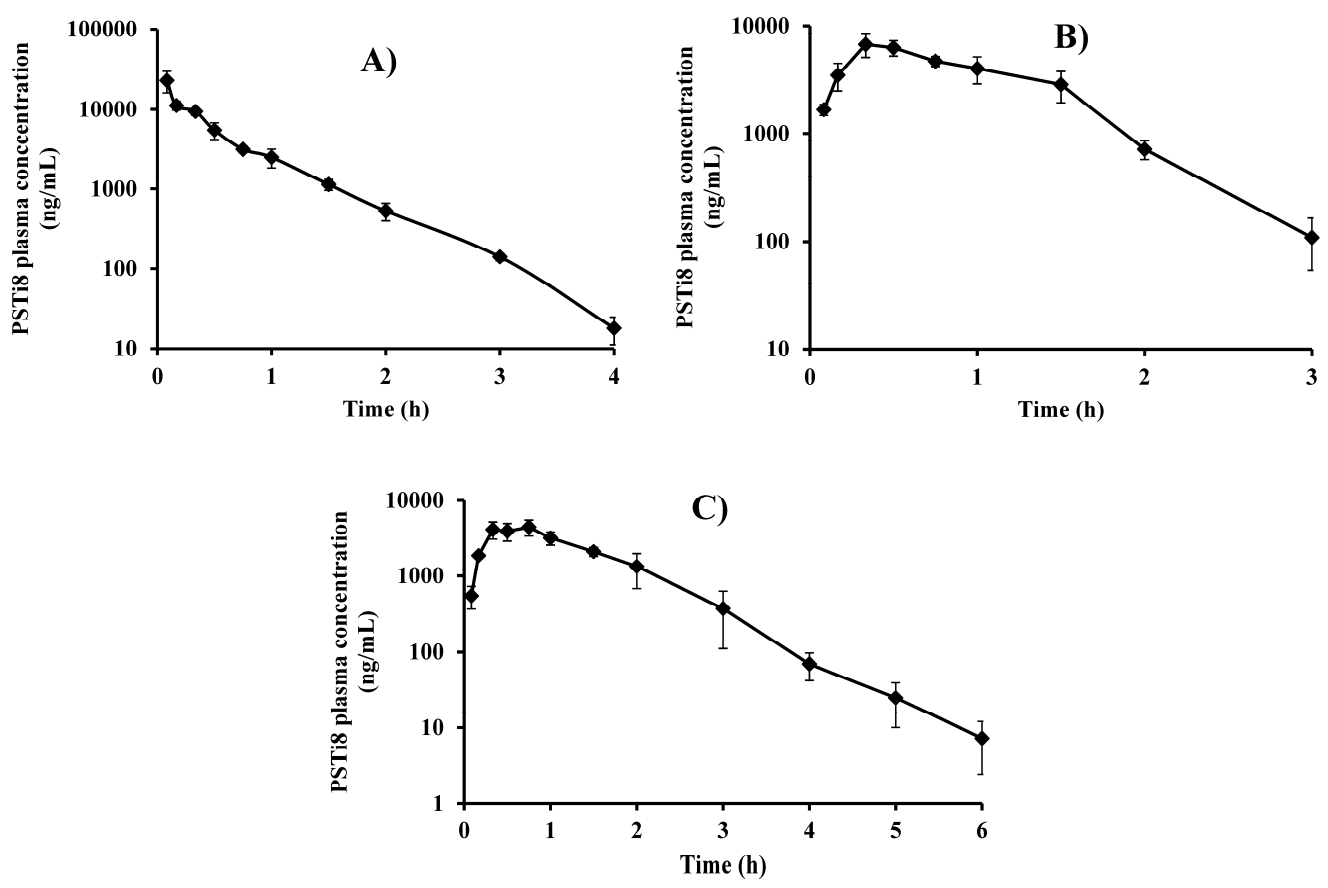

Figure 2. Pharmacokinetic studies of the PSTi8 peptide in different routes of administration in male SD rats. Plasma concentration against time profiles of the PSTi8 peptide at a dose of $5 \mathrm{mg} / \mathrm{kg}$, after (A) i.v., (B) i.p. and (C) s.c. administration to each group. Data are represented in $n=6$ with the mean \pm SD.

\subsubsection{Dose Proportionality PK Studies}

The PSTi8 peptide is safe and non-toxic at acute (50 and $250 \mathrm{mg} / \mathrm{kg}$, i.p.) high doses in mice [8]. In order to understand the dose proportionality PK behavior, PSTi8 was administered i.p. in male SD rats at a dose of 10 and $20 \mathrm{mg} / \mathrm{kg}$ to each group. The plasma concentration vs. time profiles and PK parameters of PSTi8 after i.p. treatment in male $\mathrm{SD}$ rats at 10 and $20 \mathrm{mg} / \mathrm{kg}$, are represented in Figure 3 and Table 3. For the nominal i.p. doses, 1:2 proportion, the $C_{\max }$ and AUC values were found in the ratio of 1.00:3.52 and 1.00:3.44, respectively (Table 3). PSTi8 undergoes non-linear pharmacokinetics in the dose proportionality study. To understand the non-linear pharmacokinetics of PSTi8, a comprehensive study of a larger number of doses and peptide clearance mechanisms are warranted.

Table 3. Pharmacokinetic parameters of the PSTi8 peptide after i.p. administration at two doses of 10 and $20 \mathrm{mg} / \mathrm{kg}$ in male SD rats. Data are represented as the mean \pm SD with $n=6$.

\begin{tabular}{ccc}
\hline Parameter & i.p. PSTi8 $\mathbf{1 0 ~} \mathbf{~ m g} / \mathbf{k g}$ & i.p. PSTi8 20 $\mathbf{~ m g} / \mathbf{k g}$ \\
\hline $\mathrm{AUC}\left(\mathrm{h}^{*} \mu \mathrm{g} / \mathrm{L}\right)$ & $32,384.05 \pm 3270.55$ & $111,486.37 \pm 30,126.00$ \\
$\mathrm{C}_{\max }(\mu \mathrm{g} / \mathrm{L})$ & $24,272.74 \pm 2681.30$ & $85,606.83 \pm 15,031.65$ \\
$\mathrm{~T}_{\max }(\mathrm{h})$ & 0.38 & 0.38 \\
$\mathrm{CL} / \mathrm{F}(\mathrm{L} / \mathrm{h} / \mathrm{kg})$ & $0.31 \pm 0.03$ & $0.19 \pm 0.06$ \\
$\mathrm{~V}_{\mathrm{d}} / \mathrm{F}(\mathrm{L} / \mathrm{kg})$ & $0.26 \pm 0.09$ & $0.15 \pm 0.03$ \\
$\mathrm{~K}_{01}-\mathrm{HL}(\mathrm{h})$ & $0.15 \pm 0.05$ & $0.14 \pm 0.03$ \\
$\mathrm{~K}_{10}-\mathrm{HL}(\mathrm{h})$ & $0.59 \pm 0.23$ & $0.56 \pm 0.09$ \\
$\mathrm{~K}_{01}(1 / \mathrm{h})$ & $4.89 \pm 1.74$ & $4.94 \pm 0.97$ \\
$\mathrm{~K}_{10}(1 / \mathrm{h})$ & $1.33 \pm 0.60$ & $1.26 \pm 0.18$ \\
\hline
\end{tabular}




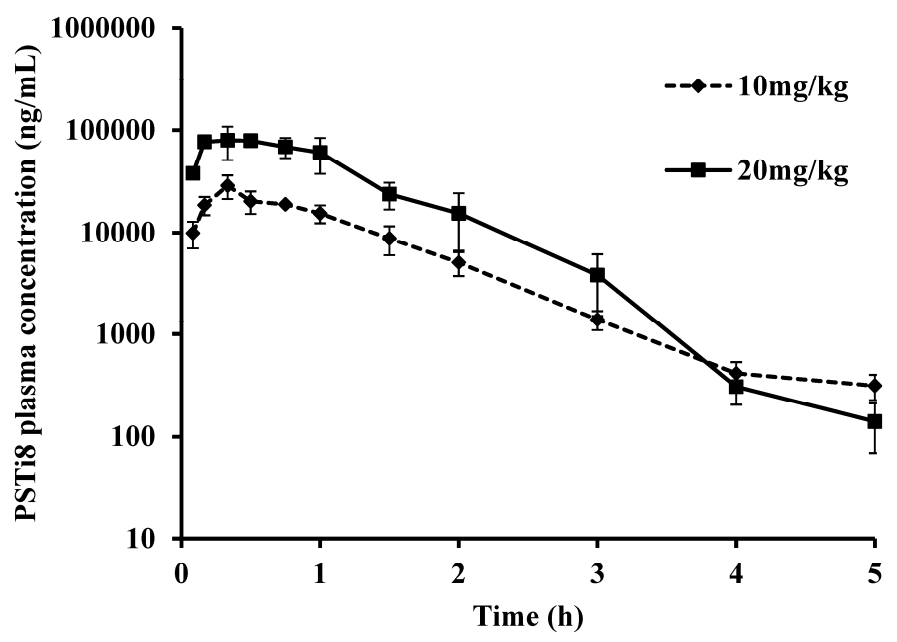

Figure 3. Dose proportionality pharmacokinetic studies of the PSTi8 peptide in male SD rats. Plasma concentration against time profiles of PSTi8 peptide after i.p. administration at 10 and $20 \mathrm{mg} / \mathrm{kg}$ to each group. Data are represented in $n=6$ with the mean \pm SD.

\subsubsection{Gender Differences in PK}

The gender disparity in the efficacy and toxicity profiles of drugs, depends primarily on the PK and metabolism pattern. Due to the differences in the physiology of men and women, there is a difference in the pharmacokinetics of drugs [15,16]. The PSTi8 was administered at a dose of $5 \mathrm{mg} / \mathrm{kg}$ i.v. and i.p. in female SD rats to each group. The PK profiles and parameters of PSTi8 after i.v. and i.p. treatment in female SD rats are represented in Figure 4A,B and Table 4. After i.p. dosing of PSTi8 in female SD rats, the $\mathrm{C}_{\max }(7004.16 \pm 216.23 \mu \mathrm{g} / \mathrm{L})$ was rapidly reached at $0.48 \mathrm{~h}\left(\mathrm{t}_{\max }\right)$ and then eliminated with $t_{1 / 2}$ of $0.32 \pm 0.02 \mathrm{~h}$. The $\mathrm{V}_{\mathrm{d}} / \mathrm{F}$ for i.v. and i.p. were found to be $0.12 \pm 0.01$ and $0.26 \pm 0.01 \mathrm{~L} / \mathrm{kg}$, respectively. The CL/F values of PSTi8 after i.v. and i.p. administration were observed as $0.53 \pm 0.10$ and $0.57 \pm 0.04 \mathrm{~L} / \mathrm{h} / \mathrm{kg}$, respectively. After i.p. treatment, the AUC of PSTi8 was found to be $9983.31 \pm 523.03 \mathrm{~h}^{*} \mu \mathrm{g} / \mathrm{L}$ in female rats. After i.v. administration, $C_{\max }$ and AUC of PSTi8 were observed as $42585.13 \pm 3706.02 \mu \mathrm{g} / \mathrm{L}$ and $9590.04 \pm 1747.10 \mathrm{~h}^{*} \mu \mathrm{g} / \mathrm{L}$, respectively, in female rats. The bioavailability of PSTi8 in female SD rats for i.p. was $91.92 \pm 6.14 \%$. There was no significant difference observed in the PK parameters and bioavailability of the PSTi8 peptide after i.p. and i.v., in male (Table 2) and female SD rats (Table 4).
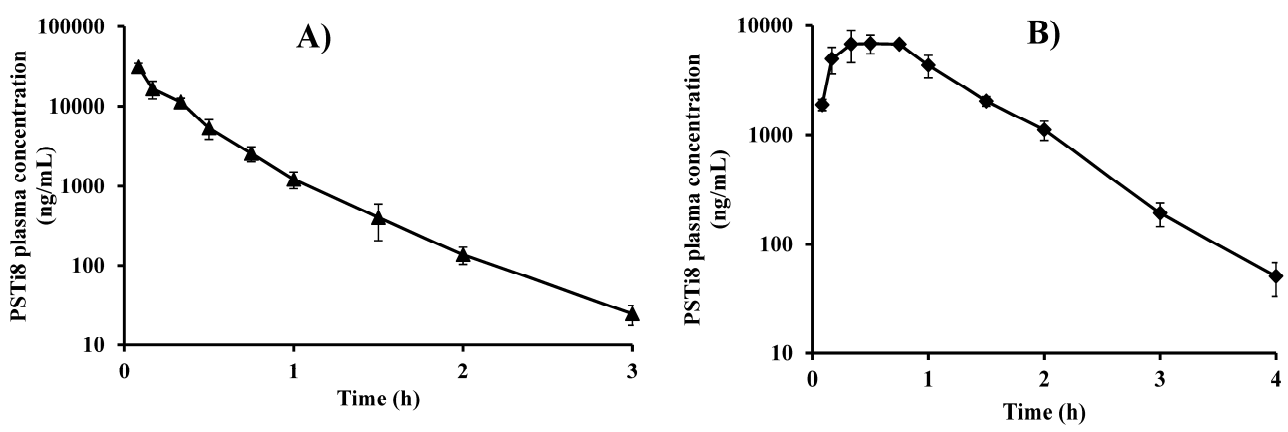

Figure 4. Pharmacokinetic studies of the PSTi8 peptide in female SD rats. Plasma concentration against time profiles of the PSTi8 peptide after at a dose of $5 \mathrm{mg} / \mathrm{kg}(\mathbf{A})$ i.v. and (B) i.p. administration to each group. Data are represented in $n=6$ with the mean \pm SD. 
Table 4. Pharmacokinetic parameters of the PSTi8 peptide after i.v. and i.p. administration at $5 \mathrm{mg} / \mathrm{kg}$ in female SD rats. Data are presented as the mean \pm SD with $n=6$.

\begin{tabular}{ccc}
\hline Parameter & i.v. PSTi8 $\mathbf{5} \mathbf{~ m g} / \mathbf{k g}$ & i.p. PSTi8 $\mathbf{~} \mathbf{~ m g} / \mathbf{k g}$ \\
\hline $\left.\mathrm{AUC}_{(\mathrm{h}}{ }^{*} \mathrm{\mu g} / \mathrm{L}\right)$ & $9590.04 \pm 1747.10$ & $8815.40 \pm 588.58$ \\
$\mathrm{C}_{\max }(\mu \mathrm{g} / \mathrm{L})$ & $42,585.13 \pm 3706.02$ & $7004.16 \pm 216.23$ \\
$\mathrm{~T}_{\max }(\mathrm{h})$ & - & 0.48 \\
$\mathrm{CL} / \mathrm{F}(\mathrm{L} / \mathrm{h} / \mathrm{kg})$ & $0.53 \pm 0.10$ & $0.57 \pm 0.04$ \\
$\mathrm{~V}_{\mathrm{d}} / \mathrm{F}(\mathrm{L} / \mathrm{kg})$ & $0.12 \pm 0.01$ & $0.26 \pm 0.01$ \\
$\mathrm{~K}_{01}-\mathrm{HL}(\mathrm{h})$ & - & $0.32 \pm 0.02$ \\
$\mathrm{~K}_{10}-\mathrm{HL}(\mathrm{h})$ & $0.16 \pm 0.02$ & $0.32 \pm 0.02$ \\
$\mathrm{~K}_{01}(1 / \mathrm{h})$ & - & $2.14 \pm 0.12$ \\
$\mathrm{~K}_{10}(1 / \mathrm{h})$ & $4.50 \pm 0.48$ & $2.19 \pm 0.18$ \\
$\mathrm{MRT}_{(\mathrm{h})}$ & $0.22 \pm 0.02$ & - \\
Bioavailability $(\%)$ & - & $91.92 \pm 6.14$ \\
\hline
\end{tabular}

\section{Materials and Methods}

\subsection{Chemicals}

PSTi8 (2427 Da and >98\% purity) was synthesized from the Life Tein LLC (Somerset, NJ, USA). LC-MS/MS grade methanol, dextran-coated charcoal, Diprotin A (IS), Dulbecco's phosphate buffer saline (DPBS), potassium ethylene diamine tetraacetic acid ( $\mathrm{K}_{2}$ EDTA), NADPH, formic acid and magnesium chloride were purchased from Sigma Aldrich (Bengaluru, India). Diethyl ether was purchased from TKM pharma (Hyderabad, India). Medium Anion Exchange (MAX) Oasis cartridges were procured from Waters Corporation (Milford, MA, USA).

\subsection{Animals}

Young, healthy SD male and female rats (200 $\pm 20 \mathrm{~g}, 9 \pm 1$ weeks) were obtained from the Laboratory Animal Facility of CSIR-CDRI. Animals were accommodated in ventilated cages at $50 \pm 10 \%$ RH and RT $24 \pm 2{ }^{\circ} \mathrm{C}$, with a regular $12 \mathrm{~h}$ light-dark cycle. Animal studies were accomplished with prior approval from the Institutional Animal Ethics Committee of CSIR-CDRI (IAEC approval no. IAEC/2012/91). Blood was withdrawn from the retroorbital plexus of rats under light ether anesthesia, using an anticoagulant (K ${ }_{2}$ EDTA) in the microcentrifuge tubes. The tubes were centrifuged at $3000 \mathrm{~g}$ for $10 \mathrm{~min}$, and the plasma was separated and kept at $-80^{\circ} \mathrm{C}$ in a freezer until analysis.

\subsection{LC-MS/MS Analysis}

A QTRAP-4000 AB Sciex (SCIEX, Concord, ON, Canada) mass spectrometer using an electrospray ionization source tandem with the Shimadzu UFLC system was utilized for the quantitative analysis. Quantification was performed for PSTi8 and IS with positive ionization mode, using prominent selected reaction monitoring transitions as 607.80/771.20 and 342.20/229.10 $\mathrm{m} / \mathrm{z}$, respectively. The chromatographic separation of PSTi8 and IS was accomplished on a Phenomenex Aqua $5 \mu$ 125A $(250 \times 4.6 \mathrm{~mm})$ column using an isocratic mode of mobile phase (methanol:0.1 \% formic acid, 50:50\% v/v) with 0.4 mL/min flow rate. The analysis run time was $10 \mathrm{~min}$ and the injection volume was $10 \mu \mathrm{L}$ for each sample. Analyst 1.6 software was used to regulate the LC-MS/MS instrument and for data quantification. The plasma sample extraction involved the SPE procedure using MAX cartridges, as previously described [6]. The LC-MS/MS bioanalytical assay of PSTi8 peptide was validated in rat plasma as per the USFDA bioanalytical method validation guidance [17]. The bioanalytical method development and validation of PSTi8 in mice plasma was recently reported [6]. The bioanalytical validation and stability studies were conducted in rat plasma, as described earlier [6]. 


\subsection{Solubility Study}

The solubility of PSTi8 peptide was conducted using the equilibrium solubility method in SGF (pH 1.2) and SIF (pH 7.4) [18]. A total of $50 \mathrm{mg}$ of PSTi8 was added to silanized glass vials containing $1 \mathrm{~mL}$ of buffer, and incubated for $1 \mathrm{~h}$ at $37^{\circ} \mathrm{C}$ in a shaking water bath to attain equilibrium. After incubation, the samples were centrifuged for $10 \mathrm{~min}$ at $12,000 \mathrm{~g}$, and supernatant was processed through SPE procedure and used for LC-MS/MS analysis.

\subsection{Plasma Stability Study}

Fresh rat plasma $(1 \mathrm{~mL})$ was used and pre-incubated in a shaking water bath at $37^{\circ} \mathrm{C}$ for $10 \mathrm{~min}$. PSTi8 was added to rat plasma at a final concentration of 1 or $5 \mu \mathrm{M}$ and then incubated for $1 \mathrm{~h}$ at $37^{\circ} \mathrm{C}$ in a shaking water bath. A total of $100 \mu \mathrm{L}$ samples were aliquoted at predetermined time points $(0,5,15,30,60,90,120$ and $240 \mathrm{~min})$, followed by SPE processing and analyzed using the validated LC-MS/MS method. The plasma stability was determined as the \% drug remaining at different time points relative to the drug at 0 min [19].

\subsection{Microsomal Metabolic Stability Study}

RLM was prepared from SD rats from our lab, as previously reported [18]. In vitro metabolic stability of PSTi8 was determined using RLM. The reaction milieu was prepared by adding $50 \mathrm{mM}$ Tris buffer ( $\mathrm{pH} 7.4), 40 \mathrm{mM} \mathrm{MgCl}_{2}$ pre-incubated at $37^{\circ} \mathrm{C}$ along with RLM $(0.5 \mathrm{mg} / \mathrm{mL})$ and spiked at a concentration $(5 \mu \mathrm{M})$ of PSTi8. The reaction was started with NADPH (1 mM) and without NADPH (negative control using Tris buffer). A total of $100 \mu \mathrm{L}$ samples were collected at $0,5,15,30,45$ and $60 \mathrm{~min}$, and the reaction was quenched with liquid nitrogen. Samples were processed with the SPE procedure and analyzed using the LC-MS/MS method. Negative control was used to assess the peptide stability in the reaction milieu and the positive control (Testosterone, $25 \mu \mathrm{M}$ ) was incubated to obtain the microsomal activity.

\subsection{Plasma Protein Binding Study}

The protein binding study of the PSTi8 peptide was conducted in rat plasma using the modified charcoal adsorption method. The suspension of dextran-coated charcoal $(0.66 \%)$ was prepared in the DPBS buffer ( $\mathrm{pH} 7.4$ ) and stirred overnight $(18 \mathrm{~h})$, before the study. PSTi8 $(2 \mu \mathrm{M}$ and $5 \mu \mathrm{M})$ was prepared in $2.5 \mathrm{~mL}$ rat plasma and pre-incubated at $37 \pm 0.5^{\circ} \mathrm{C}$ for $15 \mathrm{~min}$ in a shaking water bath. The exact volume of the charcoal suspension, the same as the plasma, was centrifuged at $3000 \mathrm{~g}$ for $15 \mathrm{~min}$ to separate DPBS. The supernatant was decanted and the pre-incubated plasma was added to the charcoal pellet-containing tubes. Plasma-containing charcoal tubes were incubated under continuous stirring up to $4 \mathrm{~h}$. A total of $200 \mu \mathrm{L}$ samples were collected at the time points of $0,5,10,20,30,45$, $60,90,120$ and $180 \mathrm{~min}$, and then centrifuged at $11,000 \mathrm{~g}$ for $2.5 \mathrm{~min}$. A total of $100 \mu \mathrm{L}$ supernatant of the centrifuged sample was separated, extracted using SPE and analyzed with LC-MS/MS. The \% peptide remaining in the supernatant plasma sample versus time points data was evaluated using the i.v. bolus two-compartment analysis model on Phoenix 6.3 WinNonlin (Pharsight Corporation, Saint Louis, MO, USA) [20,21]. The model is defined by the bi-exponential Equation (1):

$$
B(t)=A 1 \exp (-\alpha t)+A 2 \exp (-\beta t)
$$

where $B(t) \%$ is the bound peptide remaining at time $t$ and where $A 1, A 2, \alpha$ and $\beta$ are constants.

\subsection{Blood-Plasma Partitioning Study}

Fresh blood was collected from SD rats and used for the blood-plasma partitioning study. The blood was pre-incubated in a shaking water bath for $10 \mathrm{~min}$ at $37 \pm 0.5^{\circ} \mathrm{C}$. The blood-plasma partitioning study was performed for PSTi8 at $0.206 \mu \mathrm{M}(0.5 \mu \mathrm{g} / \mathrm{mL})$ and $0.412 \mu \mathrm{M}(1 \mu \mathrm{g} / \mathrm{mL})$ concentrations. During the study, the fresh rat plasma was separated 
from the same batch of whole blood. During the incubation time course, $250 \mu \mathrm{L}$ aliquots of incubated whole blood samples were collected at different time points $(0,15,30$ and $60 \mathrm{~min})$ and centrifuged at 10,000 $\mathrm{g}$ for $5 \mathrm{~min}$ at RT to obtain the plasma. At each time point, $100 \mu \mathrm{L}$ aliquot of the reference plasma sample was collected. Both, $100 \mu \mathrm{L}$ aliquot of generated plasma and reference plasma were processed and analyzed using the LC-MS/MS method. For the determination of hematocrit $(\mathrm{Hc})$, heparinized whole blood $(1.0 \mathrm{~mL})$ was taken in a hematocrit tube and centrifuged at $2000 \mathrm{~g}$ for $30 \mathrm{~min}$. The Hc for the whole blood was calculated by using Equation (2) [21,22].

$$
H c=\frac{\text { Volume of blood cells }}{\text { Total blood volume }}
$$

The $K_{R B C / P L}$ for PSTi8 was determined from the following Equation (3):

$$
K_{R B C / P L}=\frac{1}{\mathrm{H}}\left[\frac{I_{R e f}}{I_{P l}}-1\right]+1
$$

where $I_{R e f}$ is the peak area ratio of reference plasma, and $I_{P l}$ is the peak area ratio of equilibrating plasma.

\subsection{Preclinical PK Evaluation}

3.9.1. Bioavailability Assessment in Different Routes of Administration

The i.v., i.p. and s.c. PK studies were conducted for PSTi8 peptide in male SD rats. Rats were distributed into three groups and each group contained 6 animals. A total of $5 \mathrm{mg} / \mathrm{kg}$ bolus dose of PSTi8 solution was administered i.v., i.p. and s.c. to each group $(n=6)$. During i.v. dosing, PSTi8 solution was injected into rats via the lateral tail vein.

\subsubsection{Dose Proportionality in PK Studies}

Male SD rats were utilized in this study and distributed into two groups (each group contained 6 animals). To each group, PSTi8 was administered i.p. at a dose of 10 and $20 \mathrm{mg} / \mathrm{kg}$ in rats.

\subsubsection{Gender Differences in PK}

Female SD rats were utilized and distributed into two groups (each group contained 6 animals). To each group, a $5 \mathrm{mg} / \mathrm{kg}$ dose of PSTi8 was administered i.v. and i.p. for PK determination.

\subsubsection{Sampling Schedule}

After dosing in rats, blood $(250 \mu \mathrm{L})$ samples were collected in EDTA containing microcentrifuge tubes at $0.08,0.16,0.33,0.50,0.75,1,2,3,4,5$ and $6 \mathrm{~h}$ time points. Plasma was separated from the blood after centrifugation and kept in a $-80{ }^{\circ} \mathrm{C}$ freezer for LCMS/MS analysis.

\subsubsection{PK Data Analysis}

The PK parameters of PSTi8 were estimated with a one-compartmental PK model in Phoenix WinNonlin. The i.p. and s.c. PK were best described by a one-compartment firstorder PK model without lag time. The i.v. PK was well explained by a one-compartment model with a bolus input and first-order elimination rate. The PK parameters include the elimination constant $\left(\mathrm{K}_{10}\right)$, absorption constant $\left(\mathrm{K}_{01}\right), \mathrm{T}_{\max }$, elimination half-life $\left(\mathrm{K}_{10}-\mathrm{HL}\right)$, absorption half-life $\left(\mathrm{K}_{01}-\mathrm{HL}\right), \mathrm{C}_{\max }$, AUC (stands for model derived $\left.\mathrm{AUC}_{0-\infty}\right), \mathrm{CL} / \mathrm{F}$, mean residence time (MRT) and $\mathrm{V}_{\mathrm{d}} / \mathrm{F}$. The bioavailability of PSTi8 was determined using the ratio between the AUC from i.p. or s.c. and i.v. routes, after normalizing the dose.

\subsection{Statistical Analysis}

All the data are represented as mean $\pm S D$, except $T_{\max }$, which is presented as the median. Statistical analysis was performed with the unpaired Student's $t$-test using the 
GraphPad Prism software version 9.0 (GraphPad Software, La Jolla, CA, USA). A $p$-value of $<0.05$ was considered as statistically significant.

\section{Conclusions}

This is the first study investigating the in vitro and in vivo pharmacokinetics of the PSTi8 peptide in rats. The PSTi8 peptide was found to be stable in rat plasma and liver microsomes. The high bioavailability of PSTi8 for i.p. administration in rats can be due to high aqueous solubility, high plasma protein binding, low clearance and low volume of distribution. The PSTi8 peptide exhibited non-linear PK in dose proportionality studies, and has no gender differences in PK between male and female SD rats. Further studies are required to investigate the PSTi8 peptide disposition mechanism involved in the nonlinear pharmacokinetics in dose proportionality studies, species differences in PK and multiple dose PK behavior. The in vitro and in vivo PK findings support the development of the PSTi8 peptide as a safe and effective antidiabetic drug.

Supplementary Materials: The following supporting information can be downloaded at, Figure S1: Representative SRM chromatograms in (A) blank rat plasma, (B) zero sample (rat plasma spiked with IS), (C) rat plasma spiked with PSTi8 (LLOQ) and IS, and (D) 5 min sample of i.v. pharmacokinetic study in male SD rats with IS; Table S1: Precision and accuracy data of QC samples PSTi8 in rat plasma; Table S2: PSTi8 peptide stability in rat plasma in different storage conditions at 3 QC levels.

Author Contributions: Conceptualization, G.R.V. and J.R.G.; methodology, G.R.V., R.A.K., S.D., M.R., A.A.S. and A.H.; software, G.R.V., M.R. and A.H.; validation, G.R.V., R.A.K., S.D., M.R., S.K.S. and A.H.; formal analysis, G.R.V., R.A.K., S.D., M.R., A.A.S., S.K.S. and A.H.; investigation, G.R.V., R.A.K., M.R. and J.R.G.; resources, M.W. and J.R.G.; data curation, G.R.V., R.A.K., S.D., M.R., A.H. and J.R.G.; writing — original draft preparation, G.R.V. and J.R.G.; writing—review and editing, G.R.V., R.A.K., S.D., M.R., A.A.S., S.K.S., A.H., M.W. and J.R.G.; visualization, G.R.V., R.A.K., S.D., M.R., A.A.S., A.H. and J.R.G.; supervision, J.R.G.; project administration, G.R.V. and J.R.G.; funding acquisition, J.R.G. All authors have read and agreed to the published version of the manuscript.

Funding: The current work was financially assisted by the Science and Engineering Research Board, Department of Science \& Technology, Govt. of India and the Council of Scientific and Industrial Research, Govt. of India.

Institutional Review Board Statement: Animal studies were accomplished with prior approval from the Institutional Animal Ethics Committee of CSIR-CDRI (IAEC approval no. IAEC/2012/91). The work was conducted in accordance with the guidelines of the Committee for the purpose of the Control and Supervision of Experiments on Animals (CPCSEA) formed by the Government of India.

Informed Consent Statement: Not applicable.

Data Availability Statement: Data supporting the reported results will be available from the corresponding author (Jiaur R. Gayen).

Acknowledgments: Authors are thankful to the Council of Scientific and Industrial Research (CSIR) for providing fellowship to G.R.V., M.R., S.K.S. and the Indian Council of Medical Research (ICMR) for fellowship to A.A.H., R.A.K. and A.H. J.R.G. would like to acknowledge the Science and Engineering Research Board, Department of Science \& Technology, Govt. of India, and the Council of Scientific and Industrial Research, Govt. of India for financial support. The CDRI communication number is 10342 .

Conflicts of Interest: The authors declare no conflict of interest.

Sample Availability: Samples of the compound are not available from the authors. 


\section{References}

1. Atlas, I.D. IDF Diabetes Atlas, 10th ed.; International Diabetes Federation: Brussels, Belgium; Available online: https:// diabetesatlas.org (accessed on 6 November 2021).

2. Saeedi, P.; Petersohn, I.; Salpea, P.; Malanda, B.; Karuranga, S.; Unwin, N.; Colagiuri, S.; Guariguata, L.; Motala, A.A.; Ogurtsova, K.; et al. Global and regional diabetes prevalence estimates for 2019 and projections for 2030 and 2045: Results from the International Diabetes Federation Diabetes Atlas, 9(th) edition. Diabetes Res. Clin. Pract. 2019, 157, 107843. [CrossRef] [PubMed]

3. Tupas, G.D.; Otero, M.C.B.; Ebhohimen, I.E.; Egbuna, C.; Aslam, M. Antidiabetic lead compounds and targets for drug development. In Phytochemicals as Lead Compounds for New Drug Discovery; Elsevier: Amsterdam, The Netherlands, 2020; pp. 127-141.

4. Yan, J.; Zhao, J.; Yang, R.; Zhao, W. Bioactive peptides with antidiabetic properties: A review. Int. J. Food Sci. Technol. 2019, 54, 1909-1919. [CrossRef]

5. Hossain, Z.; Valicherla, G.R.; Gupta, A.P.; Syed, A.A.; Riyazuddin, M.; Chandra, S.; Siddiqi, M.I.; Gayen, J.R. Discovery of pancreastatin inhibitor PSTi8 for the treatment of insulin resistance and diabetes: Studies in rodent models of diabetes mellitus Sci. Rep. 2018, 8, 8715. [CrossRef] [PubMed]

6. Valicherla, G.R.; Riyazuddin, M.; Shahi, S.; Gupta, A.P.; Syed, A.A.; Husain, A.; Gayen, J.R. LC-ESI-MS/MS assay development and validation of a novel antidiabetic peptide PSTi8 in mice plasma using SPE: An application to pharmacokinetics. J. Pharm. Biomed. Anal. 2020, 180, 113074. [CrossRef] [PubMed]

7. Valicherla, G.R.; Gupta, A.P.; Hossain, Z.; Riyazuddin, M.; Syed, A.A.; Husain, A.; Lahiri, S.; Dave, K.M.; Gayen, J.R. Pancreastatin inhibitor, PSTi8 ameliorates metabolic health by modulating AKT/GSK-3beta and PKClambda/zeta/SREBP1c pathways in high fat diet induced insulin resistance in peri-/post-menopausal rats. Peptides 2019, 120, 170147. [CrossRef] [PubMed]

8. Gupta, A.P.; Singh, P.; Garg, R.; Valicherla, G.R.; Riyazuddin, M.; Syed, A.A.; Hossain, Z.; Gayen, J.R. Pancreastatin inhibitor activates AMPK pathway via GRP78 and ameliorates dexamethasone induced fatty liver disease in C57BL/6 mice. Biomed. Pharmacother. 2019, 116, 108959. [CrossRef] [PubMed]

9. Gupta, A.P.; Syed, A.A.; Garg, R.; Goand, U.K.; Singh, P.; Riyazuddin, M.; Valicherla, G.R.; Husain, A.; Gayen, J.R. Pancreastatin inhibitor PSTi8 attenuates hyperinsulinemia induced obesity and inflammation mediated insulin resistance via MAPK/NOX3-JNK pathway. Eur. J. Pharmacol. 2019, 864, 172723. [CrossRef]

10. Gupta, A.P.; Garg, R.; Singh, P.; Goand, U.K.; Syed, A.A.; Valicherla, G.R.; Riyazuddin, M.; Mugale, M.N.; Gayen, J.R. Pancreastatin inhibitor PSTi8 protects the obesity associated skeletal muscle insulin resistance in diet induced streptozotocin-treated diabetic mice. Eur. J. Pharmacol. 2020, 881, 173204. [CrossRef]

11. Verma, P.; Vijayaraghavan, R. Preclinical investigation of the pharmacokinetics, metabolism, and protein and red blood cell binding of DRDE-07: A prophylactic agent against sulphur mustard. Acta Pharm. Sin. B 2014, 4, 394-401. [CrossRef]

12. Yuan, J.; Yang, D.C.; Birkmeier, J.; Stolzenbach, J. Determination of protein binding by in vitro charcoal adsorption. J. Pharmacokinet. Biopharm. 1995, 23, 41-55. [CrossRef]

13. Bohnert, T.; Gan, L.S. Plasma protein binding: From discovery to development. J. Pharm. Sci. 2013, 102, 2953-2994. [CrossRef] [PubMed]

14. Davies, B.; Morris, T. Physiological parameters in laboratory animals and humans. Pharm. Res. 1993, 10, 1093-1095. [CrossRef] [PubMed]

15. Wahajuddin; Singh, S.P.; Jain, G.K. Gender differences in pharmacokinetics of lumefantrine and its metabolite desbutyllumefantrine in rats. Biopharm. Drug Dispos. 2012, 33, 229-234. [CrossRef] [PubMed]

16. Madla, C.M.; Gavins, F.K.H.; Merchant, H.A.; Orlu, M.; Murdan, S.; Basit, A.W. Let's talk about sex: Differences in drug therapy in males and females. Adv. Drug Deliv. Rev. 2021, 175, 113804. [CrossRef] [PubMed]

17. FDA. FDA Guidance for Industry: Bioanalytical Method Validation US Department of Health and Human Services; CDER, Food and Drug Administration: Rockville, MD, USA, 2018

18. Riyazuddin, M.; Valicherla, G.R.; Husain, A.; Hussain, M.K.; Shukla, M.; Katekar, R.; Gupta, A.P.; Singh, P.; Banerjee, D.; Hajela, K.; et al. Elucidation of pharmacokinetics of novel DNA ligase I inhibitor, S012-1332 in rats: Integration of in vitro and in vivo findings. J. Pharm. Biomed. Anal. 2019, 162, 205-214. [CrossRef] [PubMed]

19. Singh, S.K.; Valicherla, G.R.; Bikkasani, A.K.; Cheruvu, S.H.; Hossain, Z.; Taneja, I.; Ahmad, H.; Raju, K.S.R.; Sangwan, N.S.; Singh S.K.; et al. Elucidation of plasma protein binding, blood partitioning, permeability, CYP phenotyping and CYP inhibition studies of Withanone using validated UPLC method: An active constituent of neuroprotective herb Ashwagandha. J. Ethnopharmacol. 2021, 270, 113819. [CrossRef] [PubMed]

20. Issar, M.; Singh, S.K.; Mishra, B.; Gupta, R.C. Pharmacokinetics, in-situ absorption and protein binding studies of a new neuroleptic agent centbutindole in rats. Eur. J. Pharm. Sci. 2003, 19, 105-113. [CrossRef]

21. Mehrotra, N.; Lal, J.; Puri, S.K.; Madhusudanan, K.P.; Gupta, R.C. In Vitro and In Vivo pharmacokinetic studies of bulaquine (analogue of primaquine), a novel antirelapse antimalarial, in rat, rabbit and monkey-highlighting species similarities and differences. Biopharm. Drug Dispos. 2007, 28, 209-227. [CrossRef] [PubMed]

22. Yu, S.; Li, S.; Yang, H.; Lee, F.; Wu, J.T.; Qian, M.G. A novel liquid chromatography/tandem mass spectrometry based depletion method for measuring red blood cell partitioning of pharmaceutical compounds in drug discovery. Rapid Commun. Mass Spectrom. 2005, 19, 250-254. [CrossRef] [PubMed] 